\title{
Serum 25-hydroxyvitamin D level, smoking and lung function in adults: the HUNT Study
}

\author{
Tricia L. Larose ${ }^{1}$, Ben M. Brumpton ${ }^{1}$, Arnulf Langhammer², \\ Carlos A. Camargo Jr ${ }^{3}$, Yue Chen ${ }^{4}$, Pål Romundstad ${ }^{1}$ and Xiao-Mei Mai ${ }^{1}$
}

Affiliations: ${ }^{1}$ Department of Public Health and General Practice, Faculty of Medicine, Norwegian University of Science and Technology, Trondheim, Norway. ${ }^{2}$ HUNT Research Centre, Faculty of Medicine, Norwegian University of Science and Technology, Verdal, Norway. ${ }^{3}$ Department of Emergency Medicine, Massachusetts General Hospital, Harvard Medical School, Boston, MA, USA. ${ }^{4}$ Department of Epidemiology and Community Medicine, University of Ottawa, Ottawa, ON, Canada.

Correspondence: Tricia L. Larose, Department of Public Health and General Practice, Faculty of Medicine, Norwegian University of Science and Technology, 7491 Trondheim, Norway. E-mail: tricia.laroseantnu.no

ABSTRACT The association between serum 25-hydroxyvitamin D (25(OH)D) level and lung function changes in the general population remains unclear.

We conducted cross-sectional $(n=1220)$ and follow-up $(n=869)$ studies to investigate the interrelationship of serum $25(\mathrm{OH}) \mathrm{D}$, smoking and lung function changes in a random sample of adults from the Nord-Trøndelag Health (HUNT) Study, Norway.

Lung function was measured using spirometry and included forced expiratory volume in $1 \mathrm{~s}$ (FEV1) \% predicted, forced vital capacity (FVC) \% pred and FEV1/FVC ratio. Multiple linear and logistic regression models estimated the adjusted difference in lung function measures or lung function decline, adjusted odds ratios for impaired lung function or development of impaired lung function and 95\% confidence intervals.

$40 \%$ of adults had serum $25(\mathrm{OH}) \mathrm{D}$ levels $<50 \mathrm{nmol} \cdot \mathrm{L}^{-1}$. Overall, those with a serum $25(\mathrm{OH}) \mathrm{D}$ level $<50 \mathrm{nmol} \cdot \mathrm{L}^{-1}$ showed worse lung function and increased odds of impaired lung function compared to the $\geqslant 50 \mathrm{nmol} \cdot \mathrm{L}^{-1}$ group. These associations tended to be stronger among ever-smokers, including greater decline in $\mathrm{FEV} 1 / \mathrm{FVC}$ ratio and greater odds of the development of impaired lung function (FEV1/FVC $<70 \%$ OR 2.4, 95\% CI 1.2-4.9). Associations among never-smokers were null. Results from cross-sectional and follow-up studies were consistent. There were no associations between serum 25(OH)D levels and lung function or lung function changes in never-smokers, whereas significant associations were observed in ever-smokers.

@ERSpublications

Lower serum 25(OH)D levels are associated with greater lung function decline and impaired lung function in smokers http://ow.ly/MaUaq

This article has supplementary material available from erj.ersjournals.com

Received: Dec 112014 | Accepted after revision: April 08 2015 | First published online: May 282015

Earn CME accreditation by answering questions about this article. You will find these at erj.ersjournals.com/misc/ cmeinfo.xhtml

Conflict of interest: None declared.

Support statement: This study was supported by the Research Council of Norway (project 201895/V50), ExtraStiftelsen Helse og Rehabilitering and Landsforeningen for hjerte-og lungesyke (the Norwegian Extra Foundation for Health and Rehabilitation and the Norwegian Heart and Lung Patient Organisation) (project 2011.2.0215) and the liason committee of the Central Norway Regional Health Authority - NTNU. Funding information for this study has been deposited with FundRef. 


\section{Introduction}

Increasing epidemiological evidence on vitamin D and respiratory health has been reported [1]. Several cross-sectional studies have reported an association between low vitamin D status and lower lung function in a general adult population [2-4]. However, findings from prospective studies in the general population are not consistent with each other [5-7].

One Danish study by Thuesen et al. [7] $(\mathrm{n}=4999)$ found a significant cross-sectional association between low levels of serum 25-hydroxyvitamin D $(25(\mathrm{OH}) \mathrm{D})$ and a higher proportion of low forced expiratory volume in $1 \mathrm{~s}(\mathrm{FEV} 1)$ defined as $<80 \%$ predicted, but a prospective association between high levels of serum 25(OH)D and adverse lung function changes. In contrast, a second Danish study, by AfZAL et al. [5] reported a prospective association between lower plasma $25(\mathrm{OH}) \mathrm{D}$ and greater decline in lung function (FEV1 \% pred and forced vital capacity (FVC) \% pred, but not in FEV1/FVC ratio). Results from the latter study were independently replicated in two general populations $(n=10116$ and $n=8391)$ [5]. Finally, a smaller prospective study of elderly men $(n=626)$ in the USA observed a significant association between serum $25(\mathrm{OH}) \mathrm{D}$ level $<50 \mathrm{nmol} \cdot \mathrm{L}^{-1}$ and lower lung function, as well increased lung function decline in current smokers [6]. In all three prospective studies, smoking status (daily, current or continuous versus never) showed a tendency towards a larger effect-estimate of the association between serum 25(OH)D levels and lung function changes [7], or modified the association between serum 25(OH)D level and lung function decline $[5,6]$. Taken together, the current state of evidence on the association between serum 25 $(\mathrm{OH}) \mathrm{D}$ levels and lung function changes in the general population remains unclear, and the potential interrelationship of serum $25(\mathrm{OH}) \mathrm{D}$ levels, smoking and lung function decline needs further investigation.

In the current study, we examined the interrelationship between serum $25(\mathrm{OH}) \mathrm{D}$ levels, smoking, lung function and lung function decline in a random sample of Norwegian adults (aged 19-55 years) using data from the Nord-Trøndelag Health (HUNT) Study. We also estimated the odds for impaired lung function and development of impaired lung function using two cut-points for $\mathrm{FEV} 1 / \mathrm{FVC}$ ratio $(<70 \%$ and less than lower limit of normal (LLN)).

\section{Materials and methods}

Subjects and study design

HUNT is a longitudinal, population-based health study of Norwegian inhabitants at latitude $64^{\circ}$ north. The HUNT study population consists of mostly Caucasian adults, aged $\geqslant 19$ years, with sociodemographic characteristics, mortality and morbidity profiles considered generally representative of Norway [8, 9]. To date, three adult HUNT surveys are complete: HUNT1 (1984-1986), HUNT2 (1995-1997) and HUNT3 (2006-2008). The target population for HUNT2 (1995-1997) included 93000 Norwegian adults aged $\geqslant 19$ years living in Nord-Trøndelag county. The participation rate was $70 \%$ [9]. Among HUNT2 participants, $~ 57 \%$ ( $\mathrm{n}=37059)$ also took part in HUNT3 (2006-2008) [8].

We established a cohort of 25616 adults aged 19-55 years at baseline who participated in both HUNT2 and HUNT3 [10]. From this cohort, we selected a 10\% random sample for measurement of serum 25(OH)D levels in blood samples collected during HUNT2 [10]. A 5\% random sample of all HUNT2 participants were selected as a subgroup for spirometry tests and followed-up to HUNT3. The size of the random samples were based on available funding and capacity at spirometry stations. From these two random samples, a total of 1293 subjects had complete data on both exposure (serum 25(OH)D) and outcome (lung function) at HUNT2 among whom 922 subjects (71\%) were followed-up with available lung function data in HUNT3.

In the cross-sectional study, we included 1220 subjects to evaluate the interrelationship between serum $25(\mathrm{OH}) \mathrm{D}$ levels, smoking and lung function or impaired lung function after missing data on smoking status was excluded $(n=75)$. In the follow-up study, we included 869 subjects to study the interrelationship between serum $25(\mathrm{OH}) \mathrm{D}$, smoking and lung function decline or development of impaired lung function after missing data on smoking status was excluded $(n=53)$. Figure 1 shows a flow chart of the study population selection, serum $25(\mathrm{OH}) \mathrm{D}$ and lung function measurements.

Blood samples were collected in HUNT2 and stored at $-70^{\circ} \mathrm{C}$ for later use. Serum $25(\mathrm{OH}) \mathrm{D}$ levels in HUNT2 were measured using DiaSorin Liaison 25(OH)D TOTAL assay (Saluggia, Italy) with detection range $10-375 \mathrm{nmol} \cdot \mathrm{L}^{-1}$, intra-assay coefficient of variation $(\mathrm{CoV}) 4 \%$ and interassay $\mathrm{CoV} 8 \%$. Serum $25(\mathrm{OH}) \mathrm{D}$ levels were categorised based on the most recent Institute of Medicine report $(<50$ or $\geqslant 50 \mathrm{nmol} \cdot \mathrm{L}^{-1}$ ) [11], or used as a continuous independent variable. As previously described [12], spirometry was performed by trained health professionals at screening stations. Instrument quality control was conducted once daily via staff lung function assessment. Participants sat in an upright position and used a nose clip [13]. Recommendations and criteria from the American Thoracic Society (ATS) were followed and applied [14]. Participants were required to give three to five acceptable and reproducible trials during which expiration continued for $\geqslant 6 \mathrm{~s}$. The best trial was selected via identification of the flow/ 


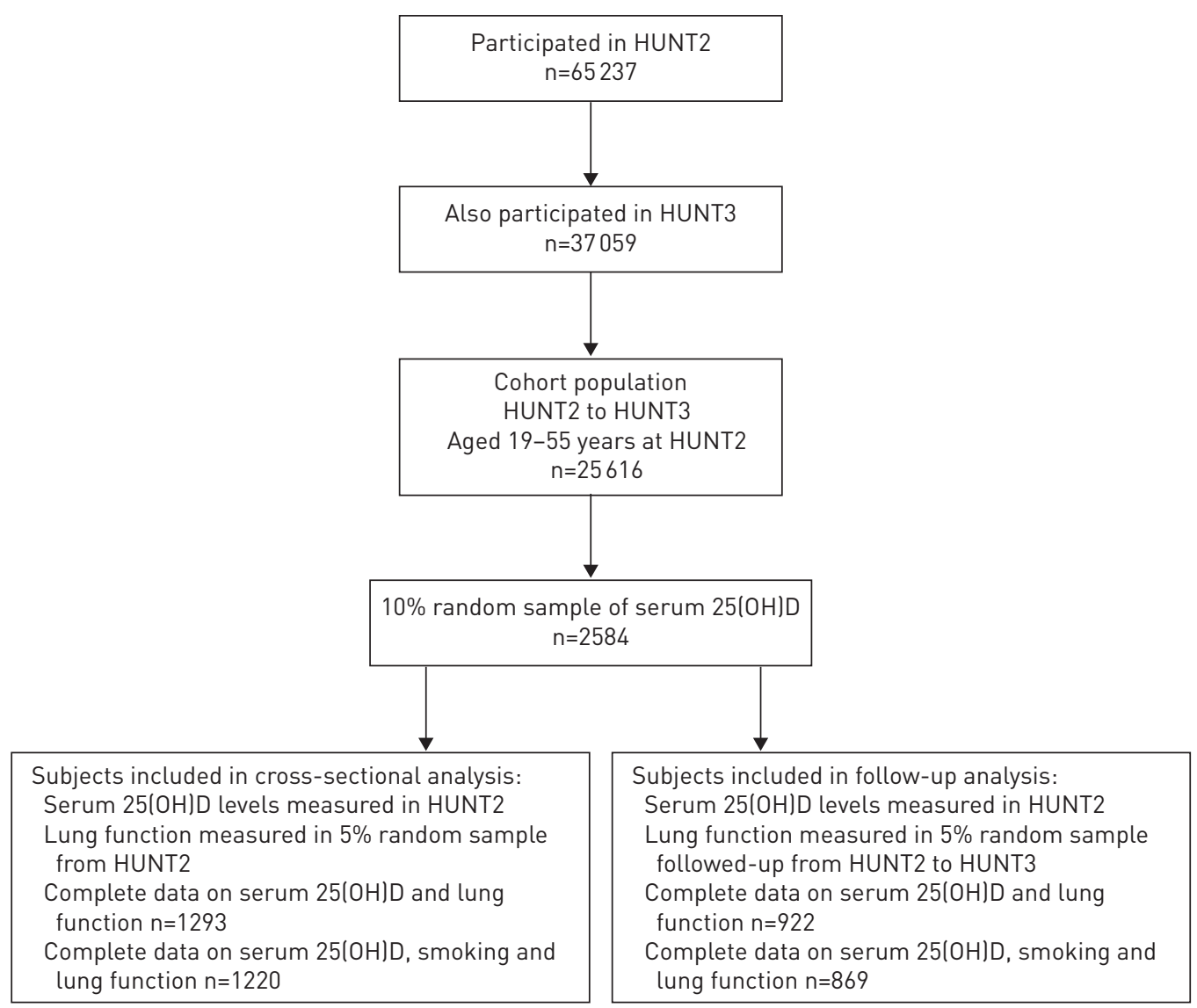

FIGURE 1 Selection of the study populations, the Nord-Trøndelag Health (HUNT) Study, 1995-1997 to 2006-2008. HUNT1 was conducted in 1984-1986, HUNT2 in 1995-1997 and HUNT3 in 2006-2008. 25(OH)D: 25-hydroxyvitamin D.

volume curve using the highest sum of FEV1 and FVC from all curves meeting acceptability criteria. Lung function measures included continuous values of $\mathrm{FEV}_{1} \%$ pred, FVC \% pred and FEV1/FVC ratio. Reference values for calculating $\mathrm{FEV}_{1} \%$ pred, FVC \% pred and LLN were based on the same HUNT population [13]. Variables included in prediction equations for lung function parameters included age, sex and height. Impaired lung function was defined as FEV1/FVC ratio $<70 \%$ or FEV1/FVC ratio $<$ LLN based on prior literature and on recommendation by the ATS $[15,16]$.

\section{Covariates}

Data on all covariates was collected during HUNT2 in clinical examination and by questionnaire. Body weight and height were measured and body mass index (BMI) was calculated $\left(\mathrm{kg} \cdot \mathrm{m}^{-2}\right)$. Smoking status was categorised as never or ever (current or former). Other variables included age (continuous), sex (female or male), height (continuous), BMI (continuous), socioeconomic status (SES) (high, low or unknown), season of blood sample collection (June-November or December-May), number of hours of light physical activity per week $(<1, \geqslant 1$ or unknown) and pack-years of smoking as a categorical $(<10$ or $\geqslant 10$ pack-years) or continuous variable. We defined smoking status by participant response to the following HUNT2 questions. Current smokers responded "yes" to "Do you smoke cigarettes daily?" and former smokers responded "no" to that question, but did not indicate that they never smoked daily. Never-smokers responded "no" to "Do you smoke cigarettes daily?" and "yes" to "never smoked daily". In our current study, smoking status was dichotomised as never or ever where ever-smokers included both current and former smokers. Participants with high SES included nonrecipients of social benefits and/or persons with no economic difficulty in the last year. Low SES included recipients of social benefits and/or persons with economic difficulties in the last year. Social benefit recipients were those who reported receiving any public welfare benefits, such as sick pay, rehabilitation/retraining/unemployment/transitional benefits, retirement/widow's pension, family supplement and/or other benefits. Participants with economic difficulty in the last year gave an affirmative response to the following question: "During the last year, has it at any time been difficult to meet the costs of food, transportation, housing and such?" 


\section{Statistical analysis}

Descriptive statistics for both study populations are presented as numbers and percentages or means and standard deviations of key baseline characteristics (table 1). The statistical analyses were performed in the overall population and separately in never- and ever-smokers based on prior information from the literature and our hypothesis. Multiple linear (tables 2 and 3 and online appendix 1) and logistic (table 4 and online appendix 2) regression models were used to estimate adjusted differences in lung function or lung function decline, adjusted odds ratios for impaired lung function or development of impaired lung function, and $95 \%$ confidence intervals. Analyses were conducted using serum $25(\mathrm{OH}) \mathrm{D}$ as a categorical $\left(<50 \mathrm{nmol} \cdot \mathrm{L}^{-1}\right.$ compared to $\left.\geqslant 50 \mathrm{nmol} \cdot \mathrm{L}^{-1}\right)$ or continuous independent variable. All regression models included BMI, SES, season and physical activity as important covariates. Outcome measures for linear models included continuous values of $\mathrm{FEV}_{1} \%$ pred, FVC \% pred and $\mathrm{FEV} 1 / \mathrm{FVC}$ ratio (\%) [15]. Outcome measures for logistic models included FEV1/FVC $<70 \%$ and FEV1/FVC $<$ LLN $[15,16]$. FEV1/FVC ratio models based on actual measurements rather than predicted equations were further adjusted for age, sex and height. To minimise possible residual confounding, we further controlled for smoking pack-years as a categorical ( $<10$ or $\geqslant 10$ pack-years) or continuous variable among ever-smokers. To test the robustness of our findings, we excluded subjects who reported ever having asthma or ever having chronic obstructive pulmonary disease (COPD), chronic bronchitis or emphysema, and repeated the analyses. Asthma status was determined by participant response to the question "Do you have or have you had asthma?", whereas COPD was determined by participant response to the question "Do you have or have you had any of the following: COPD, chronic bronchitis or emphysema?" We used Stata (version 13.1; StataCorp, College Station, TX, USA) for all statistical analyses.

\section{Ethics}

The regional committee for medical research ethics granted ethics approval for this study. All participants gave informed written consent.

TABLE 1 Baseline characteristics in a random sample of Norwegian adults, Nord-Trøndelag Health (HUNT) Study, 1995-1997 (cross-sectional study) to 2006-2008 (follow-up study)

Cross-sectional study

\begin{tabular}{|c|c|c|}
\hline $\begin{array}{l}\text { Subjects } n \\
\text { Age years }\end{array}$ & $\begin{array}{c}1220 \\
40 \pm 8.7\end{array}$ & $\begin{array}{c}869 \\
40 \pm 8.7\end{array}$ \\
\hline \multicolumn{3}{|l|}{ Sex } \\
\hline Female & $683(56)$ & $491(56)$ \\
\hline Male & $537(44)$ & $378(44)$ \\
\hline 25(OH)D level nmol. $\mathrm{L}^{-1}$ & $58 \pm 23.2$ & $57 \pm 22.4$ \\
\hline$\geqslant 50.0$ & $734(60)$ & 505 (58) \\
\hline$<50.0$ & $486(40)$ & $364(42)$ \\
\hline Body mass index $\mathrm{kg} \cdot \mathrm{m}^{-2}$ & $26 \pm 3.7$ & $26 \pm 3.7$ \\
\hline \multicolumn{3}{|l|}{ Socioeconomic status } \\
\hline High & $623(51)$ & $438(50)$ \\
\hline Low & $462(38)$ & 330 (38) \\
\hline Unknown & $135(11)$ & $101(12)$ \\
\hline \multicolumn{3}{|l|}{ Season } \\
\hline June-November & $535(44)$ & 328 (38) \\
\hline December-May & $685(56)$ & $541(62)$ \\
\hline \multicolumn{3}{|l|}{ Physical activity $h \cdot$ week $^{-1}$} \\
\hline$\geqslant 1$ & $798(65)$ & $569(66)$ \\
\hline$<1$ & $271(22)$ & $186(21)$ \\
\hline Unknown & $151(13)$ & $114(13)$ \\
\hline \multicolumn{3}{|l|}{ Smoking status } \\
\hline Never & $525(43)$ & $370(43)$ \\
\hline Ever & 695 (57) & 499 (57) \\
\hline FEV $1 \%$ pred & $98 \pm 13.7$ & $98 \pm 13.3$ \\
\hline FVC \% pred & $100 \pm 12.2$ & $100 \pm 11.8$ \\
\hline FEV1/FVC ratio & $0.8 \pm 0.1$ & $0.8 \pm 0.1$ \\
\hline
\end{tabular}

Data are presented as mean \pm SD or $n(\%)$, unless otherwise stated. 25(OH)D: 25-hydroxyvitamin D; FEV1: forced expiratory volume in $1 \mathrm{~s}$; \% pred: \% predicted; FVC: forced vital capacity. 
TABLE 2 Crude and adjusted differences in lung function measures by serum 25-hydroxyvitamin D (25(OH)D) levels and stratified by smoking status in a random sample of Norwegian adults, the Nord-Trøndelag Health (HUNT) Study, 1995-1997 (cross-sectional study)

\begin{tabular}{|c|c|c|c|c|c|c|c|}
\hline & \multirow[t]{2}{*}{ Subjects $\mathrm{n}(\%)$} & \multicolumn{2}{|c|}{ FEV $1 \%$ pred } & \multicolumn{2}{|c|}{ FVC \% pred } & \multicolumn{2}{|c|}{ FEV $_{1} /$ FVC ratio $\%$} \\
\hline & & Crude & Adjusted & Crude & Adjusted & Crude & Adjusted \\
\hline Overall & 1220 & & & & & & \\
\hline $\begin{array}{l}25(\mathrm{OH}) \mathrm{D}<50.0 \mathrm{nmol} \cdot \mathrm{L}^{-1 \#} \\
\text { Each } 25-\mathrm{nmol} \cdot \mathrm{L}^{-1} \text { reduction }\end{array}$ & $487(40)$ & $\begin{array}{l}-2.4(-4.0--0.8) \\
-1.8(-2.6--0.9)\end{array}$ & $\begin{array}{l}-2.0(-3.7--0.4) \\
-1.6(-2.5--0.7)\end{array}$ & $\begin{array}{l}-1.5(-2.9--0.1) \\
-1.1(-1.8--0.4)\end{array}$ & $\begin{array}{c}-1.3(-2.8-0.2) \\
-1.0(-1.8--0.2)\end{array}$ & $\begin{array}{c}-0.6(-1.4-0.2) \\
-0.5(-0.9--0.1)\end{array}$ & $\begin{array}{c}-0.6(-1.4-0.1) \\
-0.5(-1.0--0.1)\end{array}$ \\
\hline Never-smokers & 525 & & & & & & \\
\hline $\begin{array}{l}25(\mathrm{OH}) \mathrm{D}<50.0 \mathrm{nmol} \cdot \mathrm{L}^{-1 \#} \\
\text { Each } 25-\mathrm{nmol} \cdot \mathrm{L}^{-1} \text { reduction }\end{array}$ & $185(35)$ & $\begin{array}{l}-0.8(-3.1-1.5) \\
-0.6(-1.8-0.6)\end{array}$ & $\begin{array}{l}-0.6(-3.2-1.9) \\
-0.3(-1.7-1.1)\end{array}$ & $\begin{array}{l}-0.9(-3.0-1.3) \\
-0.4(-1.5-0.7)\end{array}$ & $\begin{array}{l}-0.6(-2.9-1.7) \\
0.0(-1.3-1.3)\end{array}$ & $\begin{array}{c}0.1(-0.9-1.1) \\
-0.2(-0.7-0.4)\end{array}$ & $\begin{array}{c}0.1(-1.0-1.2) \\
-0.2(-0.8-0.4)\end{array}$ \\
\hline $\begin{array}{l}\text { Ever-smokers } \\
25(\mathrm{OH}) \mathrm{D}<50.0 \mathrm{nmol} \cdot \mathrm{L}^{-1 \#} \\
\text { Each } 25-\mathrm{nmol} \cdot \mathrm{L}^{-1} \text { reduction }\end{array}$ & $\begin{array}{c}695 \\
302(43)\end{array}$ & $\begin{array}{l}-3.2(-5.3--1.1) \\
-2.4(-3.5--1.3)\end{array}$ & $\begin{array}{l}-3.0(-5.3--0.8) \\
-2.4(-3.6--1.2)\end{array}$ & $\begin{array}{l}-2.0(-3.8--0.1) \\
-1.6(-2.6--0.6)\end{array}$ & $\begin{array}{l}-2.0(-4.0--0.1) \\
-1.7(-2.8--0.7)\end{array}$ & $\begin{array}{l}-0.9(-1.9-0.2) \\
-0.5(-1.1-0.0)\end{array}$ & $\begin{array}{c}-0.9(-2.0-0.1) \\
-0.7(-1.2--0.1)\end{array}$ \\
\hline
\end{tabular}

Data are presented as difference in lung function $\beta(95 \% \mathrm{Cl})$, unless otherwise stated. Multiple linear regression models adjusted for body mass index, socioeconomic status, season and physical activity. Model for forced expiratory volume in $1 \mathrm{~s}$ (FEV 1 /forced vital capacity (FVC) ratio (\%) adjusted for age, sex and height. Model for overall study population adjusted for smoking status. $\%$ pred: $\%$ predicted. ${ }^{\#}$ : reference group was serum $25(\mathrm{OH}) \mathrm{D}$ level $\geqslant 50 \mathrm{nmol} \cdot \mathrm{L}^{-1}$.

TABLE 3 Crude and adjusted difference in lung function decline by serum 25-hydroxyvitamin D (25/OH)D) levels and stratified by smoking status in a random sample of Norwegian adults after an 11-year follow-up, the Nord-Trøndelag Health (HUNT) Study, 1995-1997 to 2006-2008 (follow-up study)

\begin{tabular}{|c|c|c|c|c|c|c|c|}
\hline & \multirow[t]{2}{*}{ Subjects $\mathrm{n}(\%)$} & \multicolumn{2}{|c|}{ FEV $1 \%$ pred } & \multicolumn{2}{|c|}{ FVC $\%$ pred } & \multicolumn{2}{|c|}{ FEV 1 FVC ratio $\%$} \\
\hline & & Crude & Adjusted & Crude & Adjusted & Crude & Adjusted \\
\hline Overall & 869 & & & & & & \\
\hline $25(\mathrm{OH}) \mathrm{D}<50.0 \mathrm{nmol} \cdot \mathrm{L}^{-1 \#}$ & $365(42)$ & $0.6(-0.7-1.9)$ & $0.3(-1.0-1.7)$ & $0.3(-0.9-1.6)$ & $-0.4(-1.7-1.0)$ & $0.4(-0.4-1.1)$ & $0.7(-0.1-1.5)$ \\
\hline Each $25-\mathrm{nmol} \cdot \mathrm{L}^{-1}$ reduction & & $0.3(-0.4-1.0)$ & $0.2(-0.6-0.9)$ & $0.4(-0.3-1.1)$ & $0.1(-0.7-0.8)$ & $0.0(-0.4-0.4)$ & $0.1(-0.3-0.6)$ \\
\hline Never-smokers & 370 & & & & & & \\
\hline $25(\mathrm{OH}) \mathrm{D}<50.0 \mathrm{nmol} \cdot \mathrm{L}^{-1 \#}$ & $140(38)$ & $-0.3(-2.1-1.4)$ & $-1.0(-3.0-0.9)$ & $0.0(-1.8-1.8)$ & $-0.6(-2.7-1.4)$ & $-0.3(-1.3-0.8)$ & $-0.3(-1.5-0.9)$ \\
\hline Each $25-\mathrm{nmol} \cdot \mathrm{L}^{-1}$ reduction & & $0.0(-1.0-1.0)$ & $-0.4(-1.5-0.8)$ & $0.4(-0.6-1.5)$ & $0.2(-1.0-1.4)$ & $-0.4(-1.0-0.2)$ & $-0.5(-1.2-0.2)$ \\
\hline Ever-smokers & 499 & & & & & & \\
\hline $25(\mathrm{OH}) \mathrm{D}<50.0 \mathrm{nmol} \cdot \mathrm{L}^{-1 \#}$ & $225(45)$ & $1.0(-0.8-2.7)$ & $0.8(-1.0-2.7)$ & $0.4(-1.3-2.1)$ & $-0.4(-2.2-1.4)$ & $0.7(-0.3-1.7)$ & $1.2(0.1-2.2)$ \\
\hline Each $25-\mathrm{nmol} \cdot \mathrm{L}^{-1}$ reduction & & $0.4(-0.6-1.3)$ & $0.3(-0.7-1.3)$ & $0.3(-0.6-1.2)$ & $-0.1(-1.1-0.9)$ & $0.2(-0.4-0.7)$ & $0.4(-0.2-0.9)$ \\
\hline
\end{tabular}

Data are presented as difference in lung function decline $\beta(95 \% \mathrm{Cl})$, unless otherwise stated. Multiple linear regression models adjusted for body mass index, socioeconomic status, season and physical activity. Model for forced expiratory volume in $1 \mathrm{~s}$ (FEV 1 )/forced vital capacity (FVC) ratio (\%) adjusted for age, sex and height. A negative coefficient indicates less decline in lung function. A positive coefficient indicates more decline in lung function. Model for overall study population adjusted for smoking status. \% pred: \% predicted. ${ }^{\#}$ : reference group was serum $25(\mathrm{OH}) \mathrm{D}$ level $\geqslant 50 \mathrm{nmol} \cdot \mathrm{L}^{-1}$. 
TABLE 4 Crude and adjusted odds ratios for the associations between serum 25-hydroxyvitamin D (25(OH)D) levels and impaired lung function or development of impaired lung function and stratified by smoking status in a random sample of Norwegian adults, the Nord-Trøndelag Health (HUNT) Study, 1996-1997 to 2006-2008

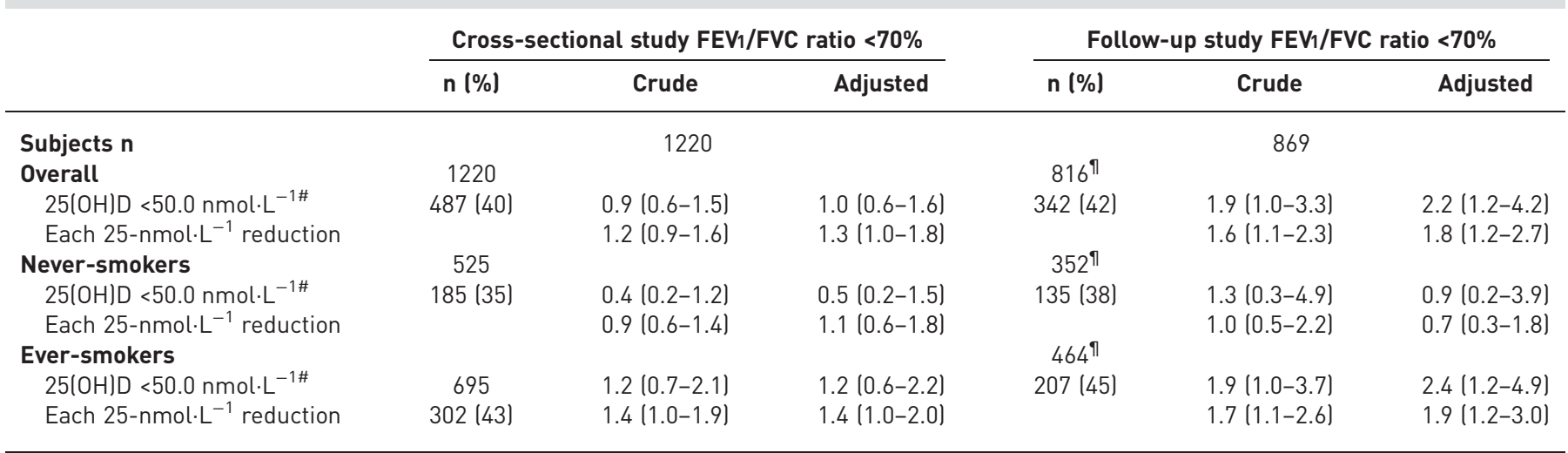

Data are presented as OR (95\% CI), unless otherwise stated. Logistic regression models for forced expiratory volume in $1 \mathrm{~s}$ (FEV 1 )/forced vital capacity (FVC) ratio <70\% adjusted for body mass index, socioeconomic status, season, physical activity, age, sex and height. Model for overall study population adjusted for smoking status. "\#: reference category was serum $25(\mathrm{OH}) \mathrm{D}$ level $\geqslant 50 \mathrm{nmol} \cdot \mathrm{L}^{-1}$; ${ }^{\Uparrow}$ : subjects with $\mathrm{FEV} / / \mathrm{FVC}$ ratio $<70 \%$ at baseline were excluded from the longitudinal analysis.

\section{Results}

A comparison between participants in the initial $(n=1293)$, cross-sectional $(n=1220)$ and follow-up $(\mathrm{n}=869)$ study samples showed that the cross-sectional sample compared to the follow-up sample had slightly higher mean serum 25(OH)D level $\left(58 \mathrm{nmol} \cdot \mathrm{L}^{-1}\right.$ versus $57 \mathrm{nmol} \cdot \mathrm{L}^{-1}$ ), a slightly higher proportion of participants with serum $25(\mathrm{OH}) \mathrm{D}$ level $\geqslant 50 \mathrm{nmol} \cdot \mathrm{L}^{-1}(60 \%$ versus $58 \%)$ and a higher proportion of participants with blood samples collected during summer months (44\% versus $38 \%$ ) at baseline (table 1). Mean lung function measures, and the distribution of sociodemographic and lifestyle factors were similar in subjects from the original, cross-sectional and follow-up samples.

In the cross-sectional study, the overall adjusted difference in lung function measures (table 2) revealed a significant association between serum $25(\mathrm{OH}) \mathrm{D}$ level $<50 \mathrm{nmol} \cdot \mathrm{L}^{-1}$ and FEV1 \% pred (OR $-2.0,95 \%$ CI $-3.7-0.4)$ compared to the $\geqslant 50 \mathrm{nmol} \cdot \mathrm{L}^{-1}$ group. We also observed significant associations between each $25 \mathrm{nmol} \cdot \mathrm{L}^{-1}$ reduction in $25(\mathrm{OH}) \mathrm{D}$ level and all three lung function measures (FEV1 \% pred, FVC \% pred and $\mathrm{FEV} 1 / \mathrm{FVC}$ ratio (\%)) in the overall study population. After stratification by smoking status (table 2), the adjusted difference in $\mathrm{FEV}_{1} \%$ pred and FVC \% pred appeared stronger among ever-smokers with serum $25(\mathrm{OH}) \mathrm{D}$ level $<50 \mathrm{nmol} \cdot \mathrm{L}^{-1}$ compared to the $\geqslant 50 \mathrm{nmol} \cdot \mathrm{L}^{-1}$ group (difference for FEV $1 \%$ pred $-3.0,95 \%$ CI $-5.3--0.8$; difference for FVC \% pred $-2.0,95 \%$ CI $-4.0--0.1$ ) (table 2). Serum $25(\mathrm{OH})$ $\mathrm{D}$ level as a continuous independent variable further supported these findings among ever-smokers. Each $25 \mathrm{nmol} \cdot \mathrm{L}^{-1}$ reduction in $25(\mathrm{OH}) \mathrm{D}$ level also showed a significant association with $\mathrm{FEV} 1 / \mathrm{FVC}$ ratio (difference $-0.7,95 \%$ CI $-1.2--0.1$ ). However, among never-smokers, results showed nonsignificant associations between serum $25(\mathrm{OH}) \mathrm{D}$ level as a categorical or continuous variable in relation to all three lung function measures ( $\mathrm{p}$-value for interaction 0.03 for continuous $25(\mathrm{OH}) \mathrm{D}$ and smoking for the FEV 1 $\%$ pred model).

In the follow-up study, the overall study population showed no clear associations between serum 25(OH)D levels and lung function changes (table 3). After stratification by smoking status, serum 25(OH)D level $<50 \mathrm{nmol} \cdot \mathrm{L}^{-1}$ showed significantly more decline in $\mathrm{FEV} 1 / \mathrm{FVC}$ ratio (difference 1.2 , 95\% CI 0.1-2.2) compared to the $\geqslant 50 \mathrm{nmol} \cdot \mathrm{L}^{-1}$ group in ever-smokers. A sensitivity analysis that excluded subjects who reported ever-asthma only $(\mathrm{n}=110)$, ever-COPD, chronic bronchitis or emphysema only $(\mathrm{n}=10)$, or both ever-asthma and ever-COPD ( $\mathrm{n}=12)$ provided additional evidence for significantly more decline in FEV1/ FVC ratio among ever-smokers with serum $25(\mathrm{OH}) \mathrm{D}$ level $<50 \mathrm{nmol} \cdot \mathrm{L}^{-1}$ (difference $1.3,95 \%$ CI $0.1-2.5$ ) (online appendix 1). However, results among never-smokers showed no associations between serum $25(\mathrm{OH})$ $\mathrm{D}$ level as a categorical or continuous independent variable in relation to all three lung function measures.

In the follow-up study, the overall study population showed increased odds for the development of impaired lung function, as measured by $\mathrm{FEV} 1 / \mathrm{FVC}$ ratio $<70 \%$, for both categorical $\left(<50 \mathrm{nmol} \cdot \mathrm{L}^{-1}\right.$ group versus $\geqslant 50 \mathrm{nmol} \cdot \mathrm{L}^{-1}$ group) and continuous (each $25-\mathrm{nmol} \cdot \mathrm{L}^{-1}$ reduction) exposure variables (table 4 ). After stratification by smoking status, increased odds for the development of impaired lung function remained among ever-smokers when serum 25(OH)D level was analysed as a categorical (OR 2.4, 95\% CI 
1.2-4.9) or continuous (OR 1.9, 95\% CI 1.2-3.0) variable (table 4). However, adjusted odds for the development of impaired lung function in never-smokers were null. Results from the cross-sectional study were supportive of the above findings (table 4) ( $\mathrm{p}$-value for the interaction 0.08 for categorical $25(\mathrm{OH}) \mathrm{D}$ and smoking for $\mathrm{FEV} 1 / \mathrm{FVC}$ ratio $<70 \%$ model).

To better understand the possible impact of smoking burden on our results, we stratified by smoking pack-years $(<10$ versus $\geqslant 10$ pack-years $)$ in the ever-smoker group and further adjusted for continuous pack-years within each pack-years group to account for within-group residual confounding. We formally tested for interaction between serum $25(\mathrm{OH}) \mathrm{D}$ level as both a categorical and continuous exposure variable and pack-years of smoking $(<10$ versus $\geqslant 10$ pack-years), using the likelihood-ratio test after estimation where $\mathrm{p}<0.10$ was considered statistically significant. We found no evidence for significant interaction between serum $25(\mathrm{OH}) \mathrm{D}$ and pack-years of smoking on lung function decline (data not presented). When LLN was used as the cut-point to define impaired lung function, results showed a similar trend, although nonsignificant, in comparison to results from table 4 (online appendix 2).

\section{Discussion}

In this general population of Norwegian adults, serum $25(\mathrm{OH}) \mathrm{D}$ levels $<50 \mathrm{nmol} \cdot \mathrm{L}^{-1}$ were associated with increased odds for development of impaired lung function compared to the $\geqslant 50 \mathrm{nmol} \cdot \mathrm{L}^{-1}$ group, after $\sim 11$ years of follow-up. This association appeared stronger in the ever-smoker group, among whom more lung function decline in FEV1/FVC ratio was also observed. Associations in never-smokers were null. Results from the cross-sectional and follow-up studies were consistent.

Our findings were supported by AFZAL et al. [5], who reported a prospective association between the lowest plasma 25(OH)D quintile and higher decline in lung function (decline in $\mathrm{FEV}_{1} \%$ pred per year 0.47, 95\% CI 0.38-0.56), as well as a higher risk for development of COPD within two independent samples of the general population. More interestingly, results from the above study were significant among smokers, whereas no significant associations were found among never-smokers [5]. Our results are also consistent with those of a longitudinal cohort of elderly men in the USA [6], which suggested that serum $25(\mathrm{OH}) \mathrm{D}$ levels $\geqslant 50 \mathrm{nmol} \cdot \mathrm{L}^{-1}$ compared to $<50 \mathrm{nmol} \cdot \mathrm{L}^{-1}$ may protect against lower lung function and more rapid lung function decline in smokers [6]. Of note, this study was conducted among male participants only aged $21-80$ years and included persons with chronic conditions such as COPD. Thus, the generalisability of findings may be limited.

Serum 25(OH)D levels may influence lung function or lung function changes through modulation of fibroblasts in respiratory epithelial cells [17] and by mediating the contraction, inflammation and remodelling of airway smooth muscle function [18].The harmful consequences of smoking on lung health are well understood, and mechanisms by which cigarette smoke contributes to lung disease include oxidative stress and pro-inflammatory responses in lung cells [19], both of which may be modulated by vitamin D [20,21]. Lung epithelial cells generate active vitamin D [22] and cigarette smoke extract has been shown to decrease the baseline conversion of inactive to active vitamin $\mathrm{D}$ in the lungs [23]. Low levels of active vitamin $\mathrm{D}$ in the lungs may interfere with the regulation of prostaglandin $\mathrm{E}_{2}$ to modulate lung fibroblasts, which play a critical role in lung tissue repair and modelling [24]. In addition to increased local inflammation, cigarette smoke can also directly induce systemic inflammation [25], and increased systemic inflammation has been linked to greater lung function decline [26]. Higher serum $25(\mathrm{OH}) \mathrm{D}$ levels may decrease circulating levels of cytokines to reduce systemic inflammation [27], whereas attenuation of inflammation may be impaired in those with lower serum 25(OH)D levels [28]. These mechanisms may explain some of the interrelationship we observed between lower serum $25(\mathrm{OH}) \mathrm{D}$ levels and adverse lung function changes among ever-smokers in our study population.

In contrast to our findings and to those of AfZAL et al. [5], another prospective Danish study by THUESEN et al. [7] found higher levels of serum $25(\mathrm{OH}) \mathrm{D}$ to be significantly associated with adverse lung function changes. Given that both Danish studies had large sample sizes derived from a general adult population in Copenhagen, the prospective results in opposite directions are not easily explained. Method-related differences based on different assays used for measurement of serum 25(OH)D levels may be one explanation. Like our study, AfzAL et al. [5] used DiaSorin radioimmunoassay for serum 25(OH)D measurement, whilst THUESEN et al. [7] used liquid chromatography for serum 25(OH)D measurement. It has been suggested that results obtained by different assay methods lack comparability, and that results from liquid chromatography are relatively high compared to those of the DiaSorin radioimmunoassay [29].

By using a standard cut-point to define airflow limitation (FEV1/FVC ratio <70\%) [30], our finding among ever-smokers suggests that lower serum $25(\mathrm{OH}) \mathrm{D}$ levels may indicate a potential risk for future development of COPD. At least one prospective study reported an association between the lowest plasma 25(OH)D quintile and risk of COPD [5]. In addition, high doses of vitamin D supplementation 
(100000 IU every 4 weeks for 1 year) were reported to reduce COPD exacerbations in a randomised trial of participants $(n=182)$ with moderate to very severe COPD and a history of recent exacerbations [31]. However, a longitudinal study found no association between baseline vitamin D status and rate of lung function decline in slow versus rapid decliners among COPD patients [32]. Smoking is the main risk factor for COPD [33] and COPD is rarely reversible [34]. As such, further evidence is needed to fully elucidate the association between serum 25(OH)D levels, smoking and COPD. More evidence on vitamin $\mathrm{D}$ supplementation as an intervention strategy to mitigate the risk of disease onset among smokers or to reduce exacerbations among COPD patients is also needed.

Our study is one of few to investigate the association between serum 25(OH)D levels and lung function changes in a general population, and also one of few studies to focus on the interrelationship between serum $25(\mathrm{OH}) \mathrm{D}$ levels, smoking and lung function changes. Baseline serum 25(OH)D levels and lung function were measured in a large random sample of adults. A broad range of serum $25(\mathrm{OH}) \mathrm{D}$ levels were captured and we also adjusted our models for seasonal variation. We followed-up $>70 \%$ of participants and characteristics between our cross-sectional and follow-up studies were similar (table 1). Thereby, we were able to minimise selection bias. Spirometry was quality controlled, and we based our reference values for prediction equations of spirometry on the same HUNT population. Trained health professionals objectively measured anthropometric data. We were able to control for a range of possible confounding factors, which included a sensitivity analysis on smoking pack-years in the ever-smoker group. Although residual confounding by smoking pack-years is not a major concern in this study, we cannot rule out the possibility that our results may be influenced by residual confounding due to unmeasured variables. A sensitivity analysis which excluded study participants who confirmed ever-asthma or ever-COPD status further confirmed our results (online appendix 1). Finally, our use of LLN as an additional cut-point for development of impaired lung function provided further information (online appendix 2), but the use of LLN may be more effective in studies with much larger sample sizes, a broader age range of participants or in diseased populations [30]. In our study, the use of LLN as a cut-point for the development of impaired lung function separated study subjects into two groups with similar mean lung function measures. Therefore, we were not able to discern strong statistical differences between these two groups. Still, LLN as a cut-point for impaired lung function should be considered in future studies as recommended by expert committees $[16,30]$.

Although high intra-individual reproducibility of serum 25(OH)D levels over time has been reported [35], the use of single serum $25(\mathrm{OH}) \mathrm{D}$ levels is one limitation of our study. Regarding smoking status, although a direct measure can be obtained by measuring cotinine levels in biological fluids, most population studies, including the HUNT Study, rely on self-report. Analytical studies that measure the concordance between self-reported smoking status and measures of cotinine show a trend toward underestimation when smoking prevalence is based on self-report [36]. However, accurate estimates of the prevalence of cigarette smoking derived from self-report have also been observed [37]. Regarding FVC measures, some participants may have been unable to fully exhale during trials, which may have contributed to an underestimation of FVC and overestimation of FEV1/FVC ratio. However, the change in lung function was the main outcome in our study, which may have minimised this measurement error. Potential COPD defined by pre-bronchodilator FEV1/FVC ratio $<70 \%$ was probably overestimated due to a lack of post-bronchodilator spirometry. Therefore, associations between low serum $25(\mathrm{OH}) \mathrm{D}$ level in ever-smokers and increased odds for development of impaired lung function relating to potential future risk of COPD must be interpreted with caution.

To summarise, in never-smokers, our data showed no clear associations between categorical or continuous serum 25(OH)D levels and all lung function measures in both cross-sectional and follow-up analysis. However, there seemed to be associations with lower serum $25(\mathrm{OH}) \mathrm{D}$ levels and more lung function decline, as well as increased odds for development of impaired lung function in ever-smokers. These findings highlight the need for continued research on serum $25(\mathrm{OH}) \mathrm{D}$ levels, smoking and lung function changes in well-designed prospective and intervention studies.

\section{Acknowledgements}

The Nord-Trøndelag Health (HUNT) Study is a collaboration between the HUNT Research Centre (Faculty of Medicine, Norwegian University of Science and Technology), the Nord-Trøndelag County Council and the Norwegian Institute of Public Health. The authors especially thank the HUNT Research Centre laboratory personnel for the measurement of serum 25(OH)D levels.

\section{References}

$1 \quad$ Hughes DA, Norton R. Vitamin D and respiratory health. Clin Exp Immunol 2009; 158: 20-25.

2 Black PN, Scragg R. Relationship between serum 25-hydroxyvitamin D and pulmonary function in the Third National Health and Nutrition Examination Survey. Chest 2005; 128: 3792-3798.

3 Berry DJ, Hesketh K, Power C, et al. Vitamin D status has a linear association with seasonal infections and lung function in British adults. Br J Nutr 2011; 106: 1433-1440. 
4 Khan S, Mai XM, Chen Y. Plasma 25-hydroxyvitamin D associated with pulmonary function in Canadian adults with excess adiposity. Am J Clin Nutr 2013; 98: 174-179.

5 Afzal S, Lange P, Bojesen SE, et al. Plasma 25-hydroxyvitamin D, lung function and risk of chronic obstructive pulmonary disease. Thorax 2014; 69: 24-31.

6 Lange NE, Sparrow D, Vokonas P, et al. Vitamin D deficiency, smoking, and lung function in the Normative Aging Study. Am J Respir Crit Care Med 2012; 186: 616-621.

7 Thuesen BH, Skaaby T, Husemoen LL, et al. The association of serum 25-OH vitamin D with atopy, asthma, and lung function in a prospective study of Danish adults. Clin Exp Allergy 2015; 45: 265-272.

8 Krokstad S, Langhammer A, Hveem K, et al. Cohort profile: The HUNT Study, Norway. Int J Epidemiol 2013; 42: 968-977.

9 Holmen J, Midthjell K, Kruger $\varnothing$, et al. The Nord-Trøndelag Health Study 1995-97 (HUNT 2): objectives, contents, methods and participation. Norsk Epidemiologi 2003; 13: 19-32.

10 Mai XM, Chen Y, Camargo CA Jr, et al. Cross-sectional and prospective cohort study of serum 25-hydroxyvitamin D level and obesity in adults: the HUNT study. Am J Epidemiol 2012; 175: 1029-1036.

11 Ross AC Taylor CL, Yaktine AL, et al. Dietary Reference Intakes for Calcium and Vitamin D. Washington, DC, National Academies Press, 2011.

12 Larose TL, Langhammer A, Chen Y, et al. Serum 25-hydroxyvitamin D levels and lung function in adults with asthma: the HUNT Study. Eur Respir J 2015; 45: 1019-1026.

13 Langhammer A, Johnsen R, Gulsvik A, et al. Forced spirometry reference values for Norwegian adults: the Bronchial Obstruction in Nord-Trøndelag Study. Eur Respir J 2001; 18: 770-779.

14 American Thoracic Society. Standardization of spirometry, 1994 update. Am J Respir Crit Care Med 1995; 152: 1107-1136.

15 Pellegrino R, Viegi G, Brusasco V, et al. Interpretative strategies for lung function tests. Eur Respir J 2005; 26: 948-968.

16 American Thoracic Society. Lung function testing: selection of reference values and interpretative strategies. Am Rev Respir Dis 1991; 144: 1202-1218.

17 Ramirez AM, Wongtrakool C, Welch T, et al. Vitamin D inhibition of pro-fibrotic effects of transforming growth factor $\beta 1$ in lung fibroblasts and epithelial cells. J Steroid Biochem Mol Biol 2010; 118: 142-150.

18 Banerjee A, Panettieri R Jr. Vitamin D modulates airway smooth muscle function. In: Litonjua A, ed. Vitamin D and the Lung: Mechanisms and Disease Associations. Springer, 2012; pp. 127-150.

19 Faux SP, Tai T, Thorne D, et al. The role of oxidative stress in the biological responses of lung epithelial cells to cigarette smoke. Biomarkers 2009; 14: Suppl. 1, 90-96.

20 Almerighi C, Sinistro A, Cavazza A, et al. 1 $\alpha, 25$-dihydroxyvitamin D3 inhibits CD40L-induced pro-inflammatory and immunomodulatory activity in human monocytes. Cytokine 2009; 45: 190-197.

21 Baeke F, Takiishi T, Korf H, et al. Vitamin D: modulator of the immune system. Curr Opin Pharmacol 2010; 10: $482-496$.

22 Hansdottir S, Monick MM, Hinde SL, et al. Respiratory epithelial cells convert inactive vitamin D to its active form: potential effects on host defense. J Immunol 2008; 181: 7090-7099.

23 Hansdottir S, Monick MM, Lovan N, et al. Smoking disrupts vitamin D metabolism in the lungs. Am J Respir Crit Care Med 2010; 181: A1425.

24 Liu X, Nelson A, Wang X, et al. Vitamin D modulates prostaglandin E2 synthesis and degradation in human lung fibroblasts. Am J Respir Cell Mol Biol 2014; 50: 40-50.

25 Bracke KR, D'hulst AI, Maes T, et al. Cigarette smoke-induced pulmonary inflammation and emphysema are attenuated in CCR6-deficient mice. J Immunol 2006; 177: 4350-4359.

26 Ahmadi-Abhari S, Kaptoge S, Luben RN, et al. Longitudinal association of C-reactive protein and lung function over 13 years: The EPIC-Norfolk study. Am J Epidemiol 2014; 179: 48-56.

27 Schleithoff SS, Zittermann A, Tenderich G, et al. Vitamin D supplementation improves cytokine profiles in patients with congestive heart failure: a double-blind, randomized, placebo-controlled trial. Am J Clin Nutr 2006; 83: 754-759.

28 Banerjee A, Panettieri R Jr. Vitamin D modulates airway smooth muscle function in COPD. Curr Opin Pharmacol 2012; 12: 266-274

29 Carter GD. Accuracy of 25-hydroxyvitamin D assays: confronting the issues. Curr Drug Targets 2011; 12 : 19-28.

30 Vestbo J, Hurd SS, Agustí AG, et al. Global strategy for the diagnosis, management, and prevention of chronic obstructive pulmonary disease: GOLD executive summary. Am J Respir Crit Care Med 2013; 187: $347-365$.

31 Lehouck A, Mathieu C, Carremans C, et al. High doses of vitamin D to reduce exacerbations in chronic obstructive pulmonary disease: a randomized trial. Ann Intern Med 2012; 156: 105-114.

32 Kunisaki KM, Niewoehner DE, Singh RJ, et al. Vitamin D status and longitudinal lung function decline in the Lung Health Study. Eur Respir J 2011; 37: 238-243.

33 Celli BR, MacNee W, ATS/ERS Task Force. Standards for the diagnosis and treatment of patients with COPD a summary of the ATS/ERS position paper. Eur Respir J 2004; 23: 932-946.

34 Raherison C, Girodet PO. Epidemiology of COPD. Eur Respir Rev 2009; 18: 213-221.

35 Sonderman JS, Munro HM, Blot WJ, et al. Reproducibility of serum 25-hydroxyvitamin D and vitamin D-binding protein levels over time in a prospective cohort study of black and white adults. Am J Epidemiol 2012; 176: 615-621.

36 Connor Gorber S, Schofield-Hurwitz S, Hardt J, et al. The accuracy of self-reported smoking: a systematic review of the relationship between self-reported and cotinine-assessed smoking status. Nicotine Tob Res 2009; 11: 12-24.

37 Wong SL, Shields M, Leatherdale S, et al. Assessment of validity of self-reported smoking status. Health Rep 2012; 23: 47-53. 